\title{
Predicting Early Maladaptive Schemas Using Baumrind's Parenting Styles
}

\author{
Ahmad Esmali Kooraneh ${ }^{1}$; Leili Amirsardari ${ }^{2, *}$ \\ ${ }^{1}$ Department of Psychology, School of Literature and Humanities, University of Maragheh, Maragheh, IR Iran \\ ${ }^{2}$ Young Researchers and Elite Club, Central Tehran Branch, Islamic Azad University, Tehran, IR Iran \\ ${ }^{*}$ Corresponding author: Leili Amirsardari, Young Researchers and Elite Club, Central Tehran Branch, Islamic Azad University, Tehran, IR Iran. Tel: +98-9373242931, Fax:+98-2833552093, \\ E-mail:1.amirsardari@yahoo.com
}

Received: June 2, 2014; Revised: December 31, 2014; Accepted: March 17, 2015

\begin{abstract}
Background: Families play an essential role in maintaining children's mental, social, and physical health. The family provides the first and the most important social context for human development.

Objectives: The present study aimed to predict early maladaptive schemas using Baumrind's parenting styles (root development).

Patients and Methods: A total of 357 undergraduate students of Islamic Azad University, Urmia Branch, Iran, were selected through random cluster sampling during 2013 and 2014. The students were assessed using the Schema Questionnaire-Short Form (SQ-SF) and the Baumrind's parenting styles inventories.

Results: The result of regression analysis showed that Baumrind's parenting styles are significant predictors of early maladaptive schemas $(\mathrm{P}<0.001)$.

Conclusions: The authoritative parenting style has some features such as showing high levels of warmth or encouraging kids to express their own possibly divergent opinions. The authoritarian parenting style, however, possesses traits such as heartlessness, impassiveness, strictness, and lack of attention to the children's developmental needs, which is not acceptable.
\end{abstract}

Keywords: Early Maladaptive Schemas; Styles of Parenting, Schema

\section{Background}

Families play an essential role in maintaining children's mental, social, and physical health. The family provides the first and the most important social context for human development. During the normal development of every child, we see a wide range of cognitive, emotional, and social changes. Almost all children will have problems during their development and this, in compatibility with the accompanying changes, stress, and conflicts, can cause behavioral, emotional, and learning problems. Most behavioral problems in children reflect the complex individual situations among family members, particularly the parents. In other words, the child's behavioral problems are due to the damaged relationships of the family members with each other and are associated with the incorrect training methods of parents and their defective interactions with their children.

The term "parenting" is derived from "pario", which means "life". The purpose of a parenting style is to help parents educate their children and reflect their attitudes toward their children and at the same time, execute the rules and regulations enacted by them. Family, as a primary context, provides the necessary resources and opportunities for the healthy development of children (1). Appropriate parenting skills are the key variables that predict children's positive outcomes in the first and middle years of life (1). The purpose of positive parenting styles is to shape the mental character and strengthen the competence of the child. The importance of these issues has led researchers to discuss parenting styles and offer a variety of methods (2) among which we can refer to the theories of Ericsson, Baumrind, and Young. Baumrind proposed three styles of parenting based on the two features of requesting (this refers to the attributes of control, monitoring, and expected mature behavior from the child) and being responsive (including support, love, and acceptance of the child) (3). In the authoritative style, parental demands are met at high levels (4) and these demands are reasonable (5). Parents allow their children to comment and enjoy independence and freedom of thought, and a warm and cordial relationship exists between the child and the parents at a high level (2). They allow their children to express their ideas, and provide the grounds for their future progress. This style of parenting can lead to increased self-regulation, compliance, and obtaining a college education (6). Nevertheless, parents who practice the authoritarian parenting style have a rigid set of rules and illustrate heartlessness, lack of attention to the developmental needs of the child, low emotional support, and strict discipline (6). This style is associated with features such as reduced admission and high control that create underlying problems such as weak social skills, low selfesteem, and aggressiveness, and will prevent them from

Copyright (C) 2015, Mazandaran University of Medical Sciences. This is an open-access article distributed under the terms of the Creative Commons Attribution-NonCommercial 4.0 International License (http://creativecommons.org/licenses/by-nc/4.0/) which permits copy and redistribute the material just in noncommercial usages, provided the original work is properly cited. 
becoming highly educated individuals (1). Parents using the permissive style have low expectations from their children (6). Acceptance, high responsiveness, relaxation in social attitudes, discipline, and customs (7), and less control from parents cause underlying problems such as aggression, low self-control, negligence, emotional problems, school dropout, and tendency toward drugs and crime; however, they also result in high confidence (1). In this parenting style, abundant love substitutes punishment by parents, both of which, in turn, may be devastating (8). Young suggests a subset of schemas that are called primary dysfunctional schemas (9). The schemafocused approach places the main emphasis on understanding the deepest levels of cognition, which is primary dysfunctional schemas, rather on automatic thoughts and underlying assumptions. Models that are focused on schemes define primary dysfunctional schemas as inclusive and extensive subjects with regard to personal and individual relationships with others that are created in childhood and last throughout a person's life and may be extended with a degree of inefficiency (9). Primary dysfunctional schemas are fundamentally implicit and unconscious contexts that are retained by the individual. Primary dysfunctional schemas are used as a model for processing experiences throughout their lives as well as for behaviors, thoughts, feelings, and their relationships with other people. In contrast to the underlying assumptions, primary dysfunctional schemas are often unconditional, and therefore, very inflexible. Essentially, primary dysfunctional schemas are authentic representations of early childhood unpleasant experiences (9). According to Young, the primary dysfunctional schemas are among the main causes of pathology generated through interpersonal experiences with close people such as parents (9). Peers are also affected by the deprivation of basic needs. These schemas represent the child's sense of self. Primary dysfunctional schemas are associated with psychologic distress levels and personality disorders. When primary dysfunctional schemas are activated due to events, the levels of emotion created directly and indirectly lead to various forms of psychologic distress including depression, anxiety, loneliness, anorexia nervosa, conflicts, and interpersonal relationship problems (9).

Young et al. identified 18 negative schemas that progress in early life (10). They stated that these schemas are divided according to five unsatisfied emotional needs called schema areas (10). The first area is disconnection and rejection. The people, whose schemas take place in this area, cannot interact in a secure and satisfying attachment with others. The schemas of this area include abandonment/instability, mistrust/abuse, emotional deprivation, defectiveness/shame, and social isolation/ alienation. The second area is impaired autonomy and performance. In this area, the person's expectation from himself/herself and environmental interaction with her/ his tangible abilities consist of separation, survival, and functioning independently, or to work successfully. The schemas of this area include dependence/incompetence, vulnerability to harm or illness, enmeshment/undeveloped self, and failure. The third area is impaired limits. In this area, individuals' internal constraints have not developed sufficiently in terms of mutual respect and restraint. The schemas of this area include entitlement/grandiosity and insufficient self-control/discipline. The fourth area is other-direction. These individuals prioritize the satisfying of the needs of others in order to receive emotional support, maintain ongoing relationships, and avoid revenge. The schemas of this area include subjugation, self-sacrifice, and approval-seeking/recognition-seeking. The fifth area is over-vigilance/inhibition. In this area, individuals place extreme emphasis on rejection of feelings and impulses in order to act according to their inflexible and internal rules even at the cost of losing joy and peace of mind. The schemas of this area include negativity/pessimism, emotional inhibition, unrelenting standards/ hypercriticalness, and punitiveness (10).

Young and Brown argued that an individual's unique experiences in childhood contribute to and influence the development of a distinct set of core beliefs about themselves and others, which they called early maladaptive schemas (11). Young believes that any childhood experience can have an effect on the formation of early maladaptive schemas (12).

\section{Objectives}

The hypothesis of this research was whether Baumrind's parenting styles (evolutionary root) were predictors of early maladaptive schemas.

\section{Materials and Methods}

In this descriptive-correlational study, samples were selected through cluster random sampling method. A total of 357 male and female students of Islamic Azad University, Urmia Branch, Iran, were selected using the Morgan table during 2013-2014. Due to the purpose and nature of this research, the best way to gather the needed information was to complete an inventory; therefore, two inventories were used in this study.

\subsection{Early Maladaptive Schema Inventory-Short Form}

The Early Maladaptive Schema inventory by Young and Brown was designed to measure early maladaptive schemas (11). The Early Maladaptive Schema inventoryshort form (SQ-SF) was created because of its briefness; however, it is used as an instrument to measure primary maladaptive schemas. The SQ-SF includes 75 items of the 205 items in the original form. These 75 items questioned 15 early maladaptive schemas of emotional deprivation (sentences 1 to 5), abandonment (sentences 6 to 10), mistrust/abuse (sentences 11 to 15), social isolation (sentences 16 to 20), defectiveness/shame (sentences 21 to 25), 
failure (sentences 26 to 30), dependence/incompetence (sentences 31 to 35), vulnerability to harm or illness (sentences 36 to 40 ), enmeshment (sentences 41 to 45 ), subjugation (sentences 46 to 50 ), self-sacrifice (sentences 51 to 55), emotional inhibition (sentences 56 to 60), unrelenting standards (sentences 61 to 65), entitlement (sentences 66 to 70), and insufficient self-control/self-discipline (sentences 71 to 75). Each one of these 75 scales of the SQ-SF is graded on a six-point scale as follows: 1) Totally wrong about me; 2) Almost wrong about me; 3) Slightly more true to false; 4) Almost true; 5) Truer about me/truer than me; and 6) Fully described me. The higher scores on each item indicate the presence of a wide range of early maladaptive schemas in the answerer (13). The reliability and validity of this instrument have been demonstrated in several studies (14). The Farsi version of this inventory was standardized in the University of Tehran, Iran, by Divandari et al. (15). Therefore, the internal consistency obtained using Cronbach's alpha was 0.97 in the female population and 0.98 in the male population (15).

\subsection{Baumrind's Parenting Inventory}

Gunty and Buri designed the Baumrind's parenting questionnaire based on the parental authority theory. It contains 30 questions with three scales (authoritative, authoritarian, and permissive), and each scale has ten items (16). Each item is rated based on the Likert scale from totally agree to totally disagree ( 5 scales) and is scored from zero to four (17). Gunty and Buri (16) reported the reliability of this tool in mothers and fathers as respectively 0.81 and 0.77 for permissive style, 0.86 and 0.85 for authoritarian style, and 0.78 and 0.88 for authoritative style. They also used the discriminant validity method for questionnaire validity that obtained the following results: authoritarian mother has a reverse association with permissive mother (-0.38) and rational authority of mother (-0.48), also authoritarian father has a reverse association with permissive father (0.50) and rational authority of father (-0.52) (16). This questionnaire has been translated into Farsi and was used by Esfandiari (18). He reported a retest reliability coefficient of $0.69,0.77$, and 0.73 for permissive, authoritarian, and authoritative styles, respectively. Psychiatrists and psychologists have also confirmed the validity of the questionnaire (18). Data analysis was performed using SPSS 18 for Windows (SPSS Inc, Chicago, Illinois, the United States) and regression analysis. Since regression analysis was used in the present research, the aim was to make use of one or more variables to predict the criterion of one or more of the predictor variables.

\section{Results}

The mean \pm standard deviations of the descriptive findings of 357 samples are illustrated in Table 1. According to Table 1, the best parenting style was authoritarian, and most schemes belong to the fields of rejection and disconnection, impaired autonomy, and over-vigilance, respectively. According to Table 2, based on the significance level of $>0.05$, permissive parenting style could not explain early maladaptive schemas in the areas of rejection and disconnection, impaired autonomy and performance, impaired limits, other-direction, and over-vigilance and inhibition. However, authoritarian parenting style could positively predict the early maladaptive schemas in the area of rejection/disconnection. This approach could explain $1.3 \%$ of the variance of early maladaptive schemas in the area of rejection/disconnection that could also positively predict early maladaptive schemas in the area of other-direction. Baumrind's authoritarian parenting style could explain $3.4 \%$ of the variance of early maladaptive schemas in the area of other-direction, but not for impaired performance and over-vigilance/inhibition. Finally, Baumrind's authoritative parenting style could negatively predict early maladaptive schemas in the area of rejection or disconnection. Thus, this approach could explain $2.6 \%$ of the variance of early maladaptive schemas in the area of rejection and disconnection, and negatively explain other-direction. Baumrind's authoritative parenting style could explain $3.4 \%$ of the variance of early maladaptive schemas in the area of other-direction, but not in impaired autonomy and performance, impaired limits, and over-vigilance/inhibition.

\begin{tabular}{ll}
\hline Table 1. Descriptive Data of Parenting Styles and Areas of Early Maladaptive Schemas & Mean \pm SD \\
\hline Variables & $20.14 \pm 10.17$ \\
\hline Age & $26.64 \pm 11.03$ \\
\hline Authoritative parenting style & $16.61 \pm 07.83$ \\
\hline Permissive parenting style & $16.86 \pm 07.28$ \\
\hline Authoritarian parenting style & $48.91 \pm 20.45$ \\
\hline Disconnection and rejection area of early maladaptive schemas & $37.52 \pm 18.92$ \\
\hline Impaired autonomy and performance area of early maladaptive schemas & $25.96 \pm 11.56$ \\
\hline Impaired limits area of early maladaptive schemas & $24.49 \pm 10.75$ \\
\hline Other-direction area of early maladaptive schemas & $27.60 \pm 10.81$ \\
\hline Over-vigilance/inhibition area of early maladaptive schemas & \\
\hline
\end{tabular}


Esmali Kooraneh A et al.

\begin{tabular}{|c|c|c|c|c|c|c|}
\hline Variables & $\mathbf{F}$ & $\mathbf{R}$ & $\mathbf{R 2}$ & $\boldsymbol{\beta}$ & B & P Value \\
\hline Permissive style and disconnection-rejection area & 00.49 & 0.030 & 0.000 & -0.030 & 52.48 & 0.48 \\
\hline Authoritarian style and disconnection-rejection area & 04.68 & 0.110 & 0.010 & -0.110 & 48.84 & 0.03 \\
\hline Authoritative style and disconnection-rejection area & 09.44 & 0.161 & 0.026 & -0.160 & 65.33 & 0.00 \\
\hline Permissive style and autonomy and performance & 00.68 & 0.040 & 0.000 & -0.040 & 39.91 & 0.40 \\
\hline Authoritarian style and autonomy and performance & 00.86 & 0.040 & 0.000 & -0.049 & 39.80 & 0.35 \\
\hline Authoritative style and autonomy and performance & 00.49 & 0.030 & 0.000 & -0.030 & 44.25 & 0.48 \\
\hline Permissive style and impaired limits & 00.41 & 0.030 & 0.000 & -0.030 & 26.91 & 0.52 \\
\hline Authoritarian style and impaired limits & 00.15 & 0.020 & 0.000 & -0.020 & 28.34 & 0.69 \\
\hline Authoritative style and impaired limits & 00.76 & 0.040 & 0.000 & -0.040 & 29.41 & 0.38 \\
\hline Permissive style and other-direction area & 00.79 & 0.040 & 0.000 & -0.040 & 28.04 & 0.37 \\
\hline Authoritarian style and other-direction area & 12.68 & 0.180 & 0.030 & -0.180 & 23.01 & 0.00 \\
\hline Authoritative style and other-direction area & 07.86 & 0.140 & 0.020 & -0.140 & 31.27 & 0.00 \\
\hline Permissive style and over-vigilance/inhibition area & 00.17 & 0.020 & 0.000 & -0.020 & 31.22 & 0.67 \\
\hline Authoritarian style and over-vigilance/inhibition area & 00.05 & 0.010 & 0.000 & -0.010 & 30.91 & 0.82 \\
\hline Authoritative style and over-vigilance/inhibition area & 00.66 & 0.040 & 0.000 & -0.040 & 32.15 & 0.41 \\
\hline
\end{tabular}

\section{Discussion}

Results showed that some of Baumrind's parenting styles are predictors of early maladaptive schemas. In addition, the results revealed that Baumrind's authoritative parenting style is a negative predictor of schemas in the area of rejection or disconnection. To explain these results using Young's approach, we can say that parents with Baumrind's authoritative parenting style have some features such as being warm and friendly, allowing children to express their own opinions, and being reasonable in expressing their demands. Hence, the schemas of this area created by rejection, abuse, and unstable, cold, and heartless manners are not effective parenting styles. On the other hand, the authoritative style is a negative predictor of schemas in the area of other-direction. As a result, the schemas of this area for parenting styles, which parents need to prioritize, did not meet the children's demands.

Another finding of this study was that the authoritarian parenting style is a good predictor of schemas in the areas of other-direction and rejection/disconnection. To explain these results, we can say that parents with authoritarian parenting style provide a base for schemas in the area of rejection/disconnection, the area that does not consider the child's need for love and safety; thus, their families are unstable, cold, ostracized, and isolated. The results show that parenting style is a predictor of schemas in the area of other-direction. Furthermore, we can say that because the authoritarian style possesses the characteristics of low acceptance and lack of attention to the emotional needs of the child, it causes a schema in the area of other-direction that emanates from neglecting children's needs (10). The results of this study have been confirmed by the studies by Young et al. (10), Gunty and Buri (16), Esmali (19), and Shahamat et al. (20).

In conclusion, conducting a research on people who have different educational levels, live in various regions, and have different cultural expressions is recommended. The limitations of this study include the use of a self-report tool (questionnaire) and a student sample; therefore, the results are not applicable to other communities. Recommendations are made to improve the quality of future research in the area of association of attachment styles and early maladaptive schema with parenting styles.

\section{Acknowledgements}

We would like to thank all of the students who participated in this study.

\section{Authors' Contributions}

Leili Amirsardari conceived and designed the evaluation tool, collected and interpreted the clinical data, performed the statistical analysis, and drafted the manuscript. Ahmad Esmali Kooraneh revised the manuscript critically for important intellectual content. Both authors read and approved the final manuscript.

\section{Declaration of Interest}

None declared.

\section{References}

1. Preschooler obesity and parenting styles of mothers and fathers: Australian national population study. Wake M, Nicholson JM, Hardy P, Smith K. Pediatrics. 2007;120(6):e1520. 
2. Mussen PH. Child development and personality. 4th ed. London, UK: Harper \& Row; 2001. pp. 636-7.

3. The influence of parenting style on adolescent competence and substance use. Baumrind D. J Early Adolesc. 1991;11(1):56.

4. Impact of parenting styles on adolescents' self-esteem and internalization of values in Spain. Martinez I, Garcia JF. Span J Psychol. 2007;10(2):338.

5. Parental Authority Styles in Adolescent-Parent Relationships. Kuhar M. Discourse Child Youth Res. 2010;3(5):321.

6. Parenting styles and overweight status in first grade. Rhee KE, Lumeng JC, Appugliese DP, Kaciroti N, Bradley RH. Pediatrics. 2006;117(6):2047.

7. Steinberg LD. Adolescence. New York: McGraw-Hill; 1996.

8. The projected image: The unconscious and the mass media. Connor JW. J Psychohist Anthropol. 1980;3(4):349.

9. Young JE. Cognitive therapy for personality disorders: A schemafocused approach. 2th ed. Sarasota: Professional Resource Press; 1994.

10. Young JE, Klosko JS, Weishaar ME. Schema therapy: A practitioner's guide. New York: Guilford Press; 2006.

11. Preliminary clinical study of the distribution of HPMA copolymers bearing doxorubicin and galactosamine. Julyan PJ, Seymour LW, Ferry DR, Daryani S, Boivin CM, Doran J, et al. J Control Release. 1999;57(3):281.

12. Young JE. Cognitive therapy for personality disorders: A schemafocused approach. Sarasota: Professional Resource Press; 1990.
13. The schema questionnaire-short form: Factor analysis and relationship between schemas and symptoms. Welburn K, Coristine M, Dagg P, Pontefract A, Jordan S. Cogn Ther Res. 2002;26(4):519.

14. Attachment and symptoms of psychopathology: early maladaptive schemas as a cognitive link? Bosmans G, Braet C, Van Vlierberghe L. Clin Psychol Psychother. 2010;17(5):374.

15. [The young schema questionnaire-short form (SQ-SF): Investigation psychometric properties and factor structure between students in Islamic Azad University, Kashmar Branch]. Divandari H, Ahi GH, Akbari H, Mahdian H. Pazhouhesh Nameye Tarbiati. 2009;5(20):103.

16. Gunty AL, Buri JR. Parental Practices and the Development of Maladaptive Schemas. Chicago: 2008.

17. Schema and parental bonding in overweight and nonoverweight female adolescents. Turner HM, Rose KS, Cooper MJ. Int J Obes (Lond). 2005;29(4):381.

18. Esfandiari GH. [Comparison of maternal parenting styles of mothers with normal children and children with behavioral disorders and the effects of parental education on children's behavioral disorders]. Tehran Iran: Tehran University; 1995.

19. Esmali A. [The structural relationship of attachment styles, parenting, early maladaptive, coping, scheme Model Young]. Tebriz Iran: Tabriz University; 2012.

20. [Study of relationship between child rearing styles and early maladaptive schemas] . Shahamat F, Sabeti A, Rezvani S. Stud Educ Psychol. 2011;11(2):239. 